\title{
The Role of Functional Assessment as an Outcome Measure in Antidementia Treatment
}

\author{
Fadi Massoud
}

\begin{abstract}
Functional assessment refers to the evaluation of performance in basic activities of daily living, instrumental activities of daily living, professional duties, and hobbies. This assessment is particularly relevant in the evaluation of cognitive impairment. In fact, functional decline represents a core feature of dementia according to the DSM-IV criteria. Clinically, functional deterioration represents a diagnostic marker, can be used to chart the course of the disease, and as a prognostic marker as it contributes significantly to caregiver burden and institutionalization. For all these reasons, functional assessment has been widely used as an outcome measure in intervention trials of Alzheimer disease (AD). Appropriate function assessment scales have been developed for use in clinical trials of $\mathrm{AD}$. Studies have shown that functional decline benefits from pharmacological interventions in AD and some other cognitive syndromes. This benefit translates into a stabilization ranging between 6 to 12 months compared to a gradual deterioration in the placebo group. There is rarely reversibility for IADL's lost. There are no functional scales specifically designed for assessment of subjects with non-AD cognitive impairment. Scales specifically developed for Mild Cognitive Impairment and other dementias are needed.
\end{abstract}

RÉSUMÉ: Le rôle de l'évaluation fonctionnelle comme critère d'évaluation des résultats du traitement de la démence. L'évaluation fonctionnelle désigne l'évaluation de la performance dans les activités de base de la vie quotidienne, les activités instrumentales de la vie quotidienne (AIVQ), les activités professionnelles et les passe-temps. Cette évaluation est particulièrement pertinente dans l'évaluation de l'atteinte cognitive. En fait, le déclin fonctionnel est un élément de base de la démence selon les critères du DSM-IV. Au point de vue clinique, la détérioration fonctionnelle est un marqueur diagnostique et elle peut être utilisée pour suivre l'évolution de la maladie ainsi que comme marqueur du pronostic parce qu'elle contribue significativement au fardeau des soignants et au placement en institution. Pour toutes ces raisons, l'évaluation fonctionnelle a été largement utilisée comme critère d'évaluation dans les essais thérapeutiques sur la maladie d'Alzheimer (MA). Des échelles d'évaluation fonctionnelle appropriées ont été développées pour les essais cliniques sur la MA. Des études ont montré que des interventions pharmacologiques dans la MA et certains autres syndromes cognitifs avaient un effet favorable sur le déclin fonctionnel. Ce bénéfice se traduit par une stabilisation qui dure entre six et douze mois alors que dans le groupe témoin sous placebo on observe une détérioration graduelle. Les pertes des AIVQ sont rarement réversibles. Il n'existe pas d'échelle fonctionnelle élaborée spécifiquement pour l'évaluation de sujets dont l'atteinte cognitive n'est pas due à la MA. Il est important de développer des échelles d'évaluation spécifiques pour évaluer l'atteinte cognitive légère et les autres démences.

Can. J. Neurol. Sci. 2007; 34: Suppl. 1 - S47-51

Functional assessment refers to the evaluation of performance in basic activities of daily living (ADL's) (bathing, dressing, toileting, transferring, continence and feeding), instrumental activities of daily living (IADL's)(ability to use telephone, shopping, meal preparation, housekeeping, transportation, managing medications and finances), professional duties, and hobbies. This assessment is particularly relevant in the evaluation of cognitive impairment. In fact, functional decline represents a core feature of dementia according to the diagnostic and statistical manual of mental disorders, 4th edition. (DSMIV) criteria. ${ }^{1}$ In Alzheimer disease (AD), it begins insidiously and deteriorates gradually. It usually progresses hierarchically, starting with demanding occupational tasks, through IADL's, and finally affects basic ADL's. ${ }^{2,3}$ In patients with AD, functional decline may lead to safety hazards (risk of fire, malnutrition, etc.) and negatively affects their quality of life. Clinically, functional deterioration represents a diagnostic marker, and can be used to chart the course of the disease (rate of decline, and reaching of significant clinical milestones). ${ }^{4,5}$ It contributes significantly to caregiver burden and institutionalization and can hence be used as a prognostic marker. For all these reasons, functional assessment has been widely used as an outcome measure in intervention trials of AD. ${ }^{6}$

From the Service de Gériatrie, Centre Hospitalier de l'Université de Montréal (CHUM), Hôpital Notre-Dame, Montréal, QC, Canada.

Received OCtober 31, 2005. ACCEPTED IN FinAl Form March 13, 2006. Reprint requests to: Fadi Massoud, Centre Hospitalier de l'Université de Montréal (CHUM), Hôpital Notre-Dame, Service de Gériatrie, 1560 Sherbrooke Est, Montréal, Quebec, H2L 4M1, Canada. 


\section{Table 1: Functional Assessment Scales Specifically Designed for Alzheimer's Disease (except for the PSMS)}

\begin{tabular}{|c|c|c|}
\hline Scale & Reference & Used in clinical trials \\
\hline $\begin{array}{l}\text { Alzheimer Disease Functional Assessment and } \\
\text { Change Scale (ADFACS) }\end{array}$ & (4) & $+(4)$ \\
\hline Disability Assessment for Dementia (DAD) & (16) & $+(22 ; 24 ; 38)$ \\
\hline $\begin{array}{l}\text { Alzheimer Disease Cooperative Study-Activities of } \\
\text { Daily Living (ADCS-ADL) }\end{array}$ & (17) & $+{ }^{(10 ; 23 ; 27-29)}$ \\
\hline Functional Performance Measure (FPR) & $(43)$ & \\
\hline The Psychogeriatric Basic ADL scale & (44) & \\
\hline Dependency Scale & (45) & \\
\hline Kitchen Task Assessment & (46) & \\
\hline $\begin{array}{l}\text { Structured Assessment of Independent Living Skills } \\
\text { (SAILS) }\end{array}$ & (47) & \\
\hline $\begin{array}{l}\text { Modified Interview for Deterioration in Daily Living } \\
\text { Activities (IDDD) }\end{array}$ & (48) & $+{ }^{(33)}$ \\
\hline Progressive Deterioration Scale (PDS) & (18) & $+{ }^{(31 ; 32 ; 34)}$ \\
\hline Direct Assessment of Functional Status & (49) & \\
\hline Functional Assessment Staging Tool (FAST) & (3) & $+{ }^{(28)}$ \\
\hline Activities of Daily Living Situation Test & $(50)$ & \\
\hline $\begin{array}{l}\text { Modified Instrumental Activities of Daily Living and } \\
\text { Physical Self-Maintenance Scale (PSMS+) }\end{array}$ & (51) & $++^{(35 ; 36)}$ \\
\hline Blessed Activities of Daily Living & (52) & \\
\hline
\end{tabular}

\section{METHODS}

This article is a background paper for the "Canadian Guidelines for the Development of Antidementia Therapies".? For the purposes of this review, the Medline database was searched from January 1966 to December 2004 using the following key words: function, dementia, Alzheimer disease, vascular dementia, mixed dementia, fronto-temporal Lobar degeneration, dementia with Lewy bodies, mild cognitive impairment, cholinesterase inhibitors, donepezil, rivastigmine, galantamine, memantine. The bibliographies of original and review articles and book chapters were also reviewed for relevant references.

\section{Determinants of Functional Abilities}

Functional decline results from a complex interaction of factors including: cognitive decline (particularly in executive function which includes volition, initiation, planning, organizing, sequencing, judgment and set shifting), behavior, motor skills, perceptual and sensory abilities, medical comorbidities, and social variables such as the support network. ${ }^{8}$ The relationship between cognitive impairment and functional autonomy remains controversial and loss of functional autonomy does not parallel the loss of cognitive function ${ }^{9,10}$ due to several reasons. A number of measures of cognitive function inadequately evaluate executive dysfunction which is a major determinant of functional performance. These measures often suffer from the floor effect and consequently do not reflect functional deterioration in the later stages of the disease. ${ }^{11}$ Several other factors may interfere in determining functional impairment. Finally, functional decline may directly result from cognition-independent basic neurological changes ${ }^{12,13}$ and pathological findings ${ }^{14,15}$ observed in $\mathrm{AD}$.

\section{Assessment of Functional Abilities in Alzheimer's Disease}

The ideal assessment tool of functional abilities in AD requires appropriate psychometric properties. It should be based on a conceptual approach to the disease which takes into account its natural history and the hierarchical loss of functional capacities. It should avoid the "ceiling" and "floor" effects and gender bias, describe the nature and degree of impairment rather than impose a dichotomous judgment on the rater (ie ordinal vs nominal), and be relevant to the population being assessed (community vs institution).

Several tools have been specifically designed for functional assessment in $\mathrm{AD}$ and have been integrated as outcome measures in clinical trials with cholinesterase inhibitors and memantine (Table 1). The most widely used scales are the Alzheimer Disease Functional Assessment and Change Scale (ADFACS) ${ }^{4}$ the Disability Assessment for Dementia (DAD), ${ }^{16}$ the Alzheimer Disease Cooperative Study-Activities of Daily Living (ADCSADL), ${ }^{17}$ and the Progressive Deterioration Scale (PDS). ${ }^{18}$

The ADFACS is based on a caregiver questionnaire and comprises six ADL items scored from 0 (no impairment) to 4 (very severe impairment) and ten IADL items (including leisure activity) scored from 0 (no impairment) to 3 (severe impairment) for a total score ranging between 0 and 54 . This scale has been shown to be sensitive to change in clinical trials of $\mathrm{AD}^{4}$ and vascular dementia. ${ }^{19,20}$ However, the sensitivity of this tool has been recently questioned by the United States Food and Drug Administration which does not consider it an appropriate outcome measure in pharmacological clinical trials. ${ }^{21}$

The DAD consists of a 40-item caregiver interview evaluating ADL's (17 items), IADL's and leisure activity (23 items). Total score represents a percentage and lower scores reflect greater impairment. It is the only functional scale to 
Table 2: Functional Assessment Scales Used in Recent Clinical Trials of Alzheimer's Disease

\begin{tabular}{|c|c|c|c|c|c|}
\hline Scale & Score & $\mathrm{ADL}$ & IADL & Ordinal vs Nominal & $\begin{array}{l}\text { Interview vs } \\
\text { Observation }\end{array}$ \\
\hline ADFACS $^{(4)}$ & $\begin{array}{c}0-54 \text { (best- } \\
\text { worst) }\end{array}$ & + & $\begin{array}{c}+ \\
\text { (including } \\
\text { leisure } \\
\text { activity) }\end{array}$ & Ordinal & Interview \\
\hline $\mathrm{DAD}^{(16)}$ & $\begin{array}{c}0 \%-100 \% \\
\text { (worst-best) }\end{array}$ & + & $\begin{array}{c}+ \\
\text { (including } \\
\text { leisure } \\
\text { activity }\end{array}$ & $\begin{array}{c}\text { Nominal } \\
\text { "Hierarchical" } \\
\text { (initiation } \\
\text { planning/organization } \\
\text { execution) }\end{array}$ & Interview \\
\hline 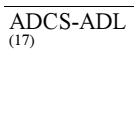 & $\begin{array}{c}0-78 \\
\text { (worst-best) }\end{array}$ & + & $\begin{array}{c}+ \\
\text { (including } \\
\text { leisure } \\
\text { activity }\end{array}$ & Ordinal & Interview \\
\hline $\mathrm{PDS}^{(18)}$ & $\begin{array}{c}0-100 \\
\text { (worst-best) }\end{array}$ & + & $\begin{array}{c}+ \\
\text { (including } \\
\text { leisure } \\
\text { activity }\end{array}$ & Ordinal & Interview \\
\hline
\end{tabular}

ADL $=$ Activities of Daily Living; IADL $=$ Instrumental Activities of Daily Living; ADFACS = Alzheimer Disease Functional Assessment and Change Scale; DAD = Disability Assessment for Dementia; ADCS-ADL = Alzheimer Disease Cooperative Study-Activities of Daily Living; PDS = Progressive Deterioration Scale

specifically evaluate the different stages involved in accomplishing a task : initiation, planning/organizing, executing. It has been used with success in clinical trials of $\mathrm{AD},{ }^{22-25}$ and vascular and mixed dementia. ${ }^{26}$

The ADCS-ADL is a caregiver interview measuring 23 ADL's and IADL's (including leisure activity) for a total score ranging from 0 to 78 (worst to best). This scale has been shown to be sensitive to change in a clinical trial of mild to moderate $\mathrm{AD} .{ }^{27}$ Modified versions have been used with success in two clinical trials in moderate to severe $\mathrm{AD}^{28,29}$ and in Mild Cognitive Impairment (MCI). ${ }^{30}$

The Progressive Deterioration Scale is based on a caregiver questionnaire and rates 29 ADL`s and IADL's (including leisure activity) on a scale ranging from 0 to 100 (worst to best). It has been used with success in two clinical trials of mild to moderate AD. ${ }^{31,32}$

Table 2 summarizes the basic properties of these scales.

\section{Functional Abilities in Clinical Trials of Alzheimer Disease}

Most pharmacological studies in AD have used function as a clinical outcome measure. In mild to moderate $\mathrm{AD}$, a pivotal clinical trial with donepezil showed stabilization of the Modified Interview for Deterioration in Daily Living (IDDD-complex task scores) at 24 weeks compared to placebo, ${ }^{33}$ which reached statistical significance for the $10 \mathrm{mg} /$ day group. In a 12-month clinical trial, Winblad et al, ${ }^{34}$ showed less deterioration in ADL's as measured by the PDS for donepezil in comparison to the placebo group. Similar results were observed in a 12-month study using a survival design which demonstrated that donepezil extends the median "time to clinically evident decline in function" as measured by the ADFACS by 5 months when compared to placebo. ${ }^{4}$ In moderate to severe $\mathrm{AD}$, a 24-week clinical trial conducted in the community ${ }^{35,36}$ showed less decline of the DAD and Modified Instrumental Activities of Daily Living and Physical Maintenance Scale (PSMS) scores in the donepezil compared to the placebo group. However, a 24-week study conducted in moderate to severe $\mathrm{AD}$ in patients in nursing homes, showed a non-statistically significant benefit in favor of donepezil on the PSMS total score. The ability of this scale to capture change in this clinical setting was questioned.

The two pivotal trials using rivastigmine have specifically evaluated functional response. A 26-week clinical trial showed that PDS scores remained near baseline in the high-dose rivastigmine group (6-12 $\mathrm{mg} / \mathrm{day})$ in comparison with the progressive decline in the placebo group. ${ }^{31} \mathrm{~A}$ significantly greater proportion of patients ( $25 \%$ vs $15 \%$ ) receiving high-dose rivastigmine demonstrated clinically meaningful improvement ( $\geq 10 \%$ improvement in the PDS score). Similar results were obtained in a second 26-week clinical trial in which high-dose rivastigmine lead to meaningful improvement in a higher number of individuals compared to placebo (29\% vs $19 \%){ }^{32}$ In a pooled analysis including data from three clinical trials, highdose rivastigmine improved the total PDS scores compared to placebo at all disease stages. ${ }^{37}$ The functional benefit appeared to be greater with disease severity, although it did not reach statistical significance.

In a 5-month clinical trial, galantamine at $16 \mathrm{mg} /$ day and 24 $\mathrm{mg} /$ day, showed maintenance of function as measured by the ADCS-ADL compared to placebo, ${ }^{27}$ with the most significant effects occurring in patients with increasing disease severity. ${ }^{10}$ Galantamine lead to a significantly better outcome on the DAD at the $32 \mathrm{mg}$ /day dose only in another 6-months multinational clinical trial..$^{23}$ In a 6-month randomized placebo-controlled trial followed by a 6 -month extension phase, there was no difference between treatment groups at 6 month on the DAD score. ${ }^{22}$ However, patients who received galantamine $24 \mathrm{mg} /$ day for 12 months had a stabilization of their DAD scores compared to the deterioration observed in the $32 \mathrm{mg} /$ day and placebo groups.

Metrifonate, a cholinesterase inhibitor that has not been approved for clinical use in $\mathrm{AD}$ demonstrated promising functional benefits in clinical trials. In a pooled analysis of three clinical trials, metrifonate significantly stabilized performance on ADL's and IADL's as measured by the DAD in comparison with placebo. ${ }^{38}$ In addition, metrifonate improved the level of executive skills in performing ADL's. ${ }^{24}$

Memantine, an noncompetitive N-methyl-D-aspartate (NMDA) receptor antagonist was used in clinical trials of moderate to severe AD. In a 28 -week clinical trial, it showed significantly less functional decline compared to placebo as measured by a modified version of the ADCS-ADL (ADCSADLsev) and the Functional Assessment Staging Tool ( FAST) scale. ${ }^{28}$ In individuals already receiving stable doses of donepezil, the addition of memantine in a 24-week trial lead to significant slowing in functional decline as measured by the ADCS-ADLsev in comparison with the addition of placebo. ${ }^{29}$

Hence, pharmacological interventions at different stages of $\mathrm{AD}$ have shown functional benefits favoring drug over placebo. This benefit can be translated into a stabilization or a slowing of functional decline ranging between 6 to 12 months.

\section{Functional Abilities in Other Cognitive Syndromes}

Functional assessment is a major diagnostic consideration in non-AD cognitive syndromes. However, there are no functional 
scales specifically designed for these syndromes. Functional scales developed for AD have been used with some success in clinical trials.

Mild Cognitive Impairment is characterized by subjective complaints, objective cognitive impairment, and general preservation of functional abilities. ${ }^{39}$ This relative sparing of function represents the fundamental distinction from dementia. However, the threshold for determination of functional decline remains controversial. There are several ongoing clinical intervention trials in MCI. In the recently completed ADCS clinical trial, a modified version of the ADCS-ADL (ADCS MCI-ADL) was used to improve sensitivity to the difficulties in IADL's that may occur in MCI. ${ }^{30}$ This scale significantly distinguished MCI subjects from normal controls at baseline.

Function was used as an outcome measure in clinical trials of Vascular Cognitive Impairment which includes "mixed dementia" (AD with significant vascular contribution) and vascular dementia. In a 6-month clinical trial in vascular and mixed dementia, galantamine lead to a significant stabilization of function as measured by the DAD in comparison with the placebo group. ${ }^{26}$ In two similarly-designed 6-month clinical trials in vascular dementia, donepezil showed uncertain results. ${ }^{19,20}$ It should be noted that patients with vascular dementia tend to remain stable both cognitively and functionally during well-recognized "plateau" periods between deteriorations. Hence, to show statistically significant benefit in favour of a drug, clinical trials need to demonstrate absolute benefit on functional scales in the active treatment arm in comparison with a stable placebo group.

In Dementia with Lewy Bodies (DLB), the only published randomized clinical trial did not assess function as an outcome measure. ${ }^{40}$ In Parkinson's Disease Dementia (PDD), a recently completed randomized clinical trial with rivastigmine used the ADCS-ADL as an outcome measure ${ }^{41}$ and showed significant benefit over placebo. Finally, the sole published randomized clinical trial in Fronto-temporal Lobar Degeneration (FTD) did not evaluate functional abilities. ${ }^{42}$

Scales that are specifically designed and validated for nonAD cognitive syndromes are needed. Scales to be eventually developed will need to be sensitive to mild change (MCI) and to take into account the motor (Mixed dementia, vascular dementia, DLB, PDD), and behavioural (DLB, PDD, FTD) limitations associated with these conditions.

\section{Conclusions}

Functional impairment is an important marker of diagnosis, progression, and prognosis of dementia. Hence, it is a valid outcome measure to be used in intervention studies. Appropriate function assessment scales have been developed for use in clinical trials of AD. Functional decline benefits from pharmacological interventions in $\mathrm{AD}$ and some other cognitive syndromes. Scales specifically developed for Mild Cognitive Impairment and other dementias are needed.

\section{DeClaration}

The author has received grant/research support from the following companies: Janssen-Ortho, Lundbeck, Novartis, and Pfizer. He has attended and received honoraria for advisory board meetings for Janssen-Ortho, Lundbeck, Novartis and
Pfizer, and has received honoraria for CME events from the following companies: Janssen-Ortho, Lundbeck, Novartis, and Pfizer.

\section{REFERENCES}

1. American Psychiatric Association. Diagnostic Criteria from DSMIV. American Psychiatric Association; 1994.

2. Reisberg B, Ferris S, Anand R, Mir R, Geibel V, DeLeon MJ, et al. Functional staging of dementia of the Alzheimer's type. Ann NY Acad Sci. 1984; 435:481-3.

3. Reisberg B. Functional assessment staging (FAST). Psychopharmacol Bull. 1988; 24(4):653-9.

4. Mohs RC, Doody RS, Morris JC, Ieni JR, Rogers SL, Perdomo CA, et al. A 1-year, placebo-controlled preservation of function survival study of donepezil in AD patients. Neurology. 2001; 57(2):481-8.

5. Galasko D, Edland SD, Morris JC, Clark C, Mohs R, Koss E. The Consortium to Establish a Registry for Alzheimer's Disease (CERAD). Part XI. Clinical milestones in patients with Alzheimer's disease followed over 3 years. Neurology. 1995; 45(8):1451-5.

6. Gauthier S, Bodick N, Erzigkeit E, Feldman H, Geldmacher DS, Huff J, et al. Activities of daily living as an outcome measure in clinical trials of dementia drugs. Position paper from the International Working Group on Harmonization of Dementia Drug Guidelines. Alzheimer Dis Assoc Disord. 1997; 11 Suppl 3:S6-7.

7. Feldman H, Gauthier S, Conn DK, Freedman M, Chris M. Canadian guidelines for the development of antidementia therapies: a conceptual summary. Can J Neurol Sci. 2006; 33:6-26.

8. Gelinas I, Auer S. Functional Autonomy. In: Gauthier S, editor. Clinical diagnosis and management of Alzheimer's disease. London: Martin Dunitz; 2001: p. 213-26.

9. Gauthier L, Gauthier S. Assessment of functional changes in Alzheimer's disease. Neuroepidemiology. 1990; 9(4):183-8.

10. Galasko D, Kershaw PR, Schneider L, Zhu Y, Tariot PN. Galantamine maintains ability to perform activities of daily living in patients with Alzheimer's disease. J Am Geriatr Soc. 2004; 52(7): 1070-6.

11. Reisberg B, Ferris SH, Torossian C, Kluger A, Monteiro I. Pharmacologic treatment of Alzheimer's disease: a methodologic critique based upon current knowledge of symptomatology and relevance for drug trials. Int Psychogeriatr. 1992; 4 Suppl 1: S9-42.

12. Franssen EH, Kluger A, Torossian CL, Reisberg B. The neurologic syndrome of severe Alzheimer's disease. Relationship to functional decline. Arch Neurol. 1993; 50(10):1029-39.

13. Franssen EH, Reisberg B, Kluger A, Sinaiko E, Boja C. Cognitionindependent neurologic symptoms in normal aging and probable Alzheimer's disease. Arch Neurol. 1991; 48(2):148-54.

14. Bobinski M, Wegiel J, Wisniewski HM, Tarnawski M, Reisberg B, Mlodzik B, et al. Atrophy of hippocampal formation subdivisions correlates with stage and duration of Alzheimer disease. Dementia. 1995; 6(4):205-10.

15. Bobinski M, Wegiel J, Tarnawski M, Bobinski M, Reisberg B, de Leon MJ et al. Relationships between regional neuronal loss and neurofibrillary changes in the hippocampal formation and duration and severity of Alzheimer disease. J Neuropathol Exp Neurol. 1997; 56(4):414-20.

16. Gelinas I, Gauthier L, McIntyre M, Gauthier S. Development of a functional measure for persons with Alzheimer's disease: the disability assessment for dementia. Am J Occup Ther. 1999; 53(5):471-81

17. Galasko D, Bennett D, Sano M, Ernesto C, Thomas R, Grundman $\mathrm{M}$, et al. An inventory to assess activities of daily living for clinical trials in Alzheimer's disease. The Alzheimer's Disease Cooperative Study. Alzheimer Dis Assoc Disord. 1997; 11 Suppl 2(3):S33-9.

18. DeJong R, Osterlund OW, Roy GW. Measurement of quality-of-life changes in patients with Alzheimer's disease. Clin Ther. 1989; 11(4):545-54 
19. Black S, Roman GC, Geldmacher DS, Salloway S, Hecker J, Burns A, et al. Efficacy and tolerability of donepezil in vascular dementia: positive results of a 24-week, multicenter, international, randomized, placebo-controlled clinical trial. Stroke. 2003; 34(10):2323-30.

20. Wilkinson D, Doody R, Helme R, Taubman K, Mintzer J, Kertesz A, et al. Donepezil in vascular dementia: a randomized, placebocontrolled study. Neurology. 2003; 61(4):479-86.

21. Blesa R. Noncognitive symptoms and long-term treatment expectations for Alzheimer disease. Alzheimer Dis Assoc Disord. 2004; 18 Suppl 1:S9-16.

22. Raskind MA, Peskind ER, Wessel T, Yuan W. Galantamine in AD: a 6-month randomized, placebo-controlled trial with a 6-month extension. The Galantamine USA-1 Study Group. Neurology. 2000; 54(12):2261-8

23. Wilcock GK, Lilienfeld S, Gaens E. Efficacy and safety of galantamine in patients with mild to moderate Alzheimer's disease: multicentre randomized controlled trial. Galantamine International-1 Study Group. BMJ. 2000; 321(7274):1445-9.

24. Gelinas I, Gauthier S, Cyrus PA. Metrifonate enhances the ability of Alzheimer's disease patients to initiate, organize, and execute instrumental and basic activities of daily living. J Geriatr Psychiatry Neurol. 2000; 13(1):9-16.

25. Raskind MA, Cyrus PA, Ruzicka BB, Gulanski BI. The effects of metrifonate on the cognitive, behavioral, and functional performance of Alzheimer's disease patients. Metrifonate Study Group. J Clin Psychiatry. 1999; 60(5):318-25.

26. Erkinjuntti T, Kurz A, Gauthier S, Bullock R, Lilienfeld S, Damaraju CV. Efficacy of galantamine in probable vascular dementia and Alzheimer's disease combined with cerebrovascular disease: a randomized trial. Lancet. 2002; 359(9314):1283-90.

27. Tariot PN, Solomon PR, Morris JC, Kershaw P, Lilienfeld S, Ding C. A 5-month, randomized, placebo-controlled trial of galantamine in AD. The Galantamine USA-10 Study Group. Neurology. 2000; 54(12):2269-76.

28. Reisberg B, Doody R, Stoffler A, Schmitt F, Ferris S, Mobius HJ. Memantine in moderate-to-severe Alzheimer's disease. N Engl J Med. 2003; 348(14):1333-41.

29. Tariot PN, Farlow MR, Grossberg GT, Graham SM, McDonald S, Gergel I. Memantine treatment in patients with moderate to severe Alzheimer disease already receiving donepezil: a randomized controlled trial. JAMA. 2004; 291(3):317-24

30. Grundman M, Petersen RC, Ferris SH, Thomas RG, Aisen PS, Bennett DA, et al. Mild cognitive impairment can be distinguished from Alzheimer disease and normal aging for clinical trials. Arch Neurol. 2004; 61(1):59-66.

31. Corey-Bloom J, Anand R, Veach J. A randomized trial evaluating the efficacy and safety of ENA 713 (rivastigmine tartrate), a new acetylcholinesterase inhibitor, in patients with mild to moderately severe Alzheimer's disease. Int J Geriatr Psychopharmacology. 1998; 1:55-65.

32. Rosler M, Anand R, Cicin-Sain A, Gauthier S, Agid Y, Dal Bianco $P$, et al. Efficacy and safety of rivastigmine in patients with Alzheimer's disease: international randomized controlled trial. BMJ. 1999; 318(7184):633-8.

33. Burns A, Rossor M, Hecker J, Gauthier S, Petit H, Moller HJ, et al. The effects of donepezil in Alzheimer's disease - results from a multinational trial. Dement Geriatr Cogn Disord. 1999; 10(3):237-44.

34. Winblad B, Engedal K, Soininen H, Verhey F, Waldemar G, Wimo A, et al. A 1-year, randomized, placebo-controlled study of donepezil in patients with mild to moderate AD. Neurology. 2001; 57(3):489-95.
35. Feldman H, Gauthier S, Hecker J, Vellas B, Subbiah P, Whalen E. A 24-week, randomized, double-blind study of donepezil in moderate to severe Alzheimer's disease. Neurology. 2001; 57(4):613-20.

36. Gauthier S, Feldman H, Hecker J, Vellas B, Emir B, Subbiah P. Functional, cognitive and behavioral effects of donepezil in patients with moderate Alzheimer's disease. Curr Med Res Opin. 2002; 18(6):347-54.

37. Potkin S, Anand R, Hartman R, Veach J, Grossberg GT. Impact of Alzheimer's disease and rivastigmine treatment on activities of daily living over the course of mild to moderately severe disease. Prog Neuropsychopharmacol Biol Psychiatry. 2002; 26:713-20.

38. Farlow MR, Cyrus PA. Metrifonate therapy in Alzheimer's disease: a pooled analysis of four randomized, double-blind, placebocontrolled trials. Dement Geriatr Cogn Disord. 2000; 11(4): 202-11.

39. Petersen RC, Smith GE, Waring SC, Ivnik RJ, Tangalos EG, Kokmen E. Mild cognitive impairment: clinical characterization and outcome. Arch Neurol. 1999; 56(3):303-8.

40. McKeith I, Del Ser T, Spano P, Emre M, Wesnes K, Anand R, et al. Efficacy of rivastigmine in dementia with Lewy bodies: a randomised, double-blind, placebo-controlled international study. Lancet. 2000; 356(9247):2031-6.

41. Emre M, Onofrj M, Tekin S, Quarg P, Lane R. Benefits of rivastigmine in Parkinson's disease dementia: results from the EXPRESS study. N Engl J Med. 2004; 351:2509-18.

42. Lebert F, Stekke W, Hasenbroekx C, Pasquier F. Frontotemporal dementia: a randomised, controlled trial with trazodone. Dement Geriatr Cogn Disord. 2004; 17(4):355-9.

43. Carswell A, Sulberg C, Carson L, Zgola J. The Functional Performance Measure for persons with Alzheimer's disease: reliability and validity. Can J Occup Ther. 1995; 62: $62-9$.

44. Laberge H, Gauthier L. L'autonomie dans les activités de base chez les personnes avec une démence de type Alzheimer et les personnes avec une dépression majeure. Rev Quebec Egrother. 1994; 3:90-5

45. Stern Y, Albert SM, Sano M, Richards M, Miller L, Folstein M, et al. Assessing patient dependence in Alzheimer's disease. J Gerontol. 1994; 49(5):M216-M222.

46. Baum C, Edwards D. Cognitive performance in senile dementia of the Alzheimer's type: the kitchen task assessment. Am J Occup Ther. 1993; 47:431-6.

47. Mahurin RK, DeBettignies BH, Pirozzolo FJ. Structured assessment of independent living skills: preliminary report of a performance measure of functional abilities in dementia. J Gerontol. 1991; 46(2):58-66.

48. Teunisse S, Derix MM, van Crevel H. Assessing the severity of dementia. Patient and caregiver. Arch Neurol. 1991; 48(3):274-7.

49. Loewenstein DA, Amigo E, Duara R, Guterman A, Hurwitz D, Berkowitz N, et al. A new scale for the assessment of functional status in Alzheimer's disease and related disorders. J Gerontol. 1989; 44(4):114-21.

50. Skurla E, Rogers JC, Sunderland T. Direct assessment of activities of daily living in Alzheimer's disease. A controlled study. J Am Geriatr Soc. 1988; 36(2):97-103.

51. Lawton MP, Brody EM. Assessment of older people: selfmaintaining and instrumental activities of daily living. Gerontologist. 1969; 9(3):179-86.

52. Blessed G, Tomlinson BE, Roth M. The association between quantitative measures of dementia and of senile change in the cerebral grey matter of elderly subjects. Br J Psychiatry. 1968; 114(512):797-811. 